\title{
TEORES DE COLESTEROL E LIPÍDIOS TOTAIS EM SEIS ESPÉCIES DE PEIXES CAPTURADOS NA REGIÃO PANTANEIRA DO ESTADO DE MATO GROSSO DO SUL
}

PRISCILA AIKO HIANE *

ADMAR FERREIRA LEAL FILHO **

MANOEL MENDES RAMOS FILHO *

MARIA ISABEL LIMA RAMOS *

O objetivo deste trabalho foi determinar os teores de colesterol e lipídios totais na porção comestível (tecido muscular) de seis espécies de peixes capturados na região pantaneira do Estado de Mato Grosso do Sul. As espécies estudadas foram o pacu (Piaractus mesopotamicus), a piranha (Pygocentrus nattereri), o dourado (Salminus maxillosus), a piraputanga (Brycon orbigynanus), o piauçu (Leporinus macrocephalus) e o pintado (Pseudoplatystoma coruscans). Usou-se o método colorimétrico de BOHAC et al. para determinação do colesterol e o da extração com solvente orgânico e gravimetria para lipídios totais. Quanto aos teores de lipídios totais, os valores médios obtidos para as seis espécies de peixes estudadas enquadraram-se na faixa de 1,0 a 6,7 g/100 g de tecido muscular dos peixes, sendo a menor concentração apresentada pelo pintado e a maior pela piraputanga. A concentração de colesterol, em $\mathrm{mg} / 100 \mathrm{~g}$ de tecido muscular (base úmida), foi mais alta para o dourado $(107,4 \mathrm{mg} / 100 \mathrm{~g})$ e mais baixa para o pintado $(51,5 \mathrm{mg} / 100 \mathrm{~g})$.

PALAVRAS-CHAVE: COLESTEROL; LIPÍDIOS TOTAIS; PEIXES.

\section{INTRODUÇÃO}

O colesterol do sangue humano depende não somente do colesterol sintetizado pelo organismo, mas também do conteúdo de gorduras (sua composição em ácidos graxos) ingeridos na dieta. O efeito dos ácidos graxos no nível de colesterol plasmático tem sido descrito por mais de 30 anos, mediante estudos epidemiológicos e experimentais $(16,18,20)$.

* Professores, Departamento de Tecnologia de Alimentos e Saúde Pública, Universidade Federal de Mato Grosso do Sul (UFMS) Campo Grande, MS. (e-mail: mmramosf@nin.ufms.br).

** Bolsista de Iniciação Científica, Programa PIBIC/CNPq, UFMS, Acadêmico do Curso de Farmácia-Bioquímica, Campo Grande, MS. 
Lipídios alimentares, ácidos graxos poliinsaturados, colesterol na dieta e suas inter-relações com os aspectos bioquímicos e fisiológicos da saúde do consumidor têm direcionado várias pesquisas para os efeitos biológicos dos óleos e gorduras $(1,8,13,18,20)$.

Para manter o colesterol sangüíneo em baixos níveis, a dieta deve ser pobre em colesterol, em gorduras e em ácidos graxos saturados (19). No correr da década de 1950 foi descoberta a influência que os ácidos graxos insaturados exercem sobre a redução das taxas séricas de colesterol, fato confirmado por observações experimentais em humanos sobre a ocorrência de moléstias cardiovasculares (15).

A partir da constatação de que os ácidos graxos polinsaturados promovem diminuição dos níveis de triglicerídios e colesterol no sangue, óleos originados de animais marinhos e/ou de água doce vêm recebendo atenção diferenciada dos pesquisadores da área médico-nutricional (13).

Pescados representam importante fonte alimentar potencialmente rica em proteínas, podendo apresentar também alto teor de colesterol, como por exemplo, os camarões (5). Dados nacionais sobre colesterol e ácidos graxos de peixes e crustáceos são escassos, principalmente de espécies de água doce.

Visando estudar as características da fração lipídica dos principais peixes encontrados na região pantaneira de Mato Grosso do Sul (MS), o presente trabalho teve como objetivo extrair e determinar os teores de colesterol e lipídios totais do óleo de seis espécies de peixes do pantanal sul-matogrossense.

\section{MATERIAL E MÉTODOS}

\subsection{MATERIAL}

Foram analisadas 6 (seis) espécies de peixes capturados no rio Miranda, região do Pantanal, Estado de Mato Grosso do Sul, no período de julho de 1999 a outubro de 2000. As espécies estudadas foram o dourado (S.maxillosus), o pacu (P.mesopotamicus), a piranha (P.nattereri), o piauçu (L.macrocephalus), a piraputanga (B.orbigynanus) e o pintado (P.coruscans). Para realização das análises, cada lote de peixe estudado foi constituído de porções comestíveis (tecido muscular) de 1,5 ou de $2,0 \mathrm{~kg}$, devidamente homogeneizadas. Foram analisados no total cinco lotes de cada espécie de peixe. 


\subsection{MÉTODOS}

\subsubsection{Umidade}

A umidade foi determinada pelo método gravimétrico, utilizando-se estufa regulada a $105^{\circ} \mathrm{C}$, de acordo com as normas analíticas do INSTITUTO ADOLFO LUTZ (14).

\subsubsection{Lipídios totais e colesterol}

A extração de lipídios das amostras de peixes foi realizada pelo método de extração a frio BLIGH e DYER (2), com $10 \mathrm{~g}$ da massa homogeneizada, obtendo-se extrato clorofórmico, com volume final de $200 \mathrm{~mL}$, para determinação de lipídios totais e colesterol.

Para a quantificação de lipídios totais foram pipetadas alíquotas de $10 \mathrm{~mL}$ do extrato clorofórmico obtido, as quais secadas e pesadas, determinandose o teor de lipídios extraídos por diferença de peso (2).

Utilizou-se a metodologia colorimétrica, descrita por BOHAC et al. $(3,4)$, para a determinação de colesterol. A partir do extrato clorofórmico preparado procedeu-se a saponificação da fração lipídica, extração do colesterol com n-hexano e reação de cor com ácido acético saturado com sulfato de ferro heptahidratado (22). A curva padrão de colesterol foi feita com colesterol purificado (Sigma Chemical Co.) e concentração na faixa de 0-200 $\mu \mathrm{g}$ (microgramas).

\subsection{ANÁLISE ESTATÍSTICA}

Para verificar as diferenças entre as concentrações de colesterol, nas seis espécies de peixes estudadas, foi realizada análise de variância, comparando-se as médias pelo Teste de Tukey no nível de significância de $5 \%(12)$.

\section{RESULTADOS E DISCUSSÃO}

Os resultados obtidos na determinação dos teores de umidade e lipídios totais em tecidos musculares das seis espécies de peixes estudadas encontram-se na Tabela 1. Os valores de lipídios totais estão expressos em $\mathrm{g} / 100 \mathrm{~g}$ de amostra integral. 


\section{TABELA 1 - TEORES DE UMIDADE E LIPÍDIOS TOTAIS EM TECIDO MUSCULAR DE PESCADOS CAPTURADOS NA REGIÃO DO PANTANAL DE MATO GROSSO DO SUL}

\begin{tabular}{lcccc}
\hline \multirow{2}{*}{$\begin{array}{c}\text { Amostras } \\
\text { analisadas }\end{array}$} & \multicolumn{2}{c}{ Umidade $(\mathrm{g} / 100 \mathrm{~g})$} & \multicolumn{2}{c}{ Lipídios totais $(\mathrm{g} / 100 \mathrm{~g})^{*}$} \\
\cline { 2 - 5 } & faixa & média $\pm \mathrm{DP}$ & faixa & média $\pm \mathrm{DP}$ \\
\hline Piranha & $74,9-80,4$ & $78,4 \pm 1,9$ & $0,9-4,1$ & $2,2 \pm 1,1$ \\
Pacu & $71,7-78,9$ & $75,9 \pm 2,5$ & $0,7-8,7$ & $2,5 \pm 3,1$ \\
Piraputanga & $68,3-77,4$ & $72,9 \pm 3,0$ & $2,8-11,4$ & $6,7 \pm 2,8$ \\
Dourado & $71,7-77,0$ & $73,9 \pm 2,4$ & $1,0-7,5$ & $4,6 \pm 2,8$ \\
Piauçu & $68,5-77,7$ & $74,1 \pm 3,1$ & $1,2-6,8$ & $3,4 \pm 1,9$ \\
Pintado & $74,5-80,2$ & $77,3 \pm 1,9$ & $0,4-1,8$ & $1,0 \pm 0,6$ \\
\hline
\end{tabular}

Média de cinco amostras analisadas em triplicata.

DP = Desvio Padrão;

* base úmida.

Verificou-se que a piraputanga apresentou o menor teor de umidade (média de $72,9 \%$ ), e a piranha o maior (média de $78,4 \%$ ).

Entre os valores médios de lipídios encontrados em trabalhos anteriores com as mesmas espécies de peixes $(7,9,10,21)$, o pintado, a piraputanga e o dourado ficaram praticamente na faixa (intervalo de variação) dos valores obtidos no presente trabalho. Já o pacu, a piranha e o piauçu apresentaram variação para as mesmas espécies de peixes. Tal fato pode ser devido à estação do ano em que as amostras foram capturadas, tamanho dos peixes utilizados nos lotes estudados e o tipo de alimentação disponível no seu habitat. Comparando estes resultados com os encontrados por FRANCO (11) verifica-se maiores valores de lipídios para o arenque $(18,10 \%)$, a merluza $(16,10 \%)$, o salmão $(13,40 \%)$ e o tubarão $(25,20 \%)$.

A Figura 1 apresenta gráfico comparativo dos teores médios de colesterol dos peixes estudados e a Tabela 2 os resultados de colesterol para as espécies de peixes da região pantaneira de Mato Grosso do Sul (analisadas em triplicata).

A concentração de colesterol, nas espécies de peixes do pantanal, variou desde níveis médios de 51,5 $\pm 1,91 \mathrm{mg} / 100 \mathrm{~g}$ (pintado) a 107,4 $\pm 30,3 \mathrm{mg} /$ $100 \mathrm{~g}$ (dourado). Observou-se que o pintado apresentou os menores valores médios de lipídios totais e de colesterol na sua porção comestível (tecido muscular, sem couro). 
FIGURA 1 - TEORES DE COLESTEROL NO TECIDO MUSCULAR DE PIRANHA (P.nattereri), PACU (P.mesopotamicus), PIRAPUTANGA (B.orbigynanus), DOURADO (S.maxillosus), PIAUÇU (L.macrocephalus) E PINTADO (P.coruscans), CAPTURADOS NA REGIÃO DO PANTANAL DE MATO GROSSO DO SUL

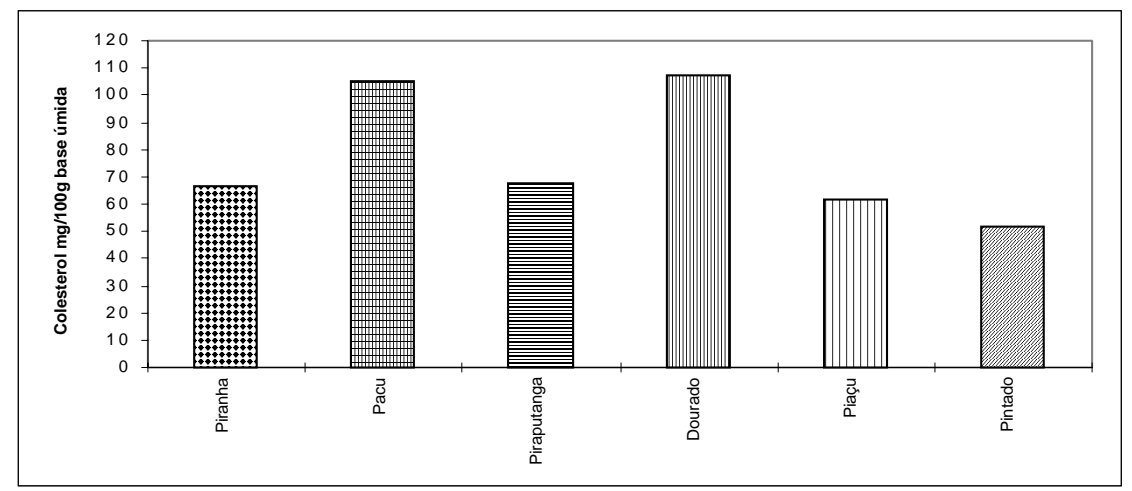

TABELA 2 - TEORES DE COLESTEROL EM TECIDO MUSCULAR DE PIRANHA ( $P$. nattereri), PACU ( $P$. mesopotamicus), PIRAPUTANGA (B.orbigynanus), DOURADO (S.maxillosus), PIAUÇU (L. macrocephalus) E PINTADO ( $P$. coruscans), CAPTURADOS NA REGIÃO DO PANTANAL DE MATO GROSSO DO SUL

\begin{tabular}{|c|c|c|c|c|}
\hline \multirow{3}{*}{$\begin{array}{l}\text { Amostras } \\
\text { analisadas }\end{array}$} & \multicolumn{4}{|c|}{ Concentração de colesterol (mg/100 g) } \\
\hline & \multicolumn{2}{|c|}{ Base Úmida } & \multicolumn{2}{|c|}{ Base seca } \\
\hline & faixa & média* $\pm D P$ & faixa & média* $\pm D P$ \\
\hline Piranha & $53,6-99,3$ & $66,7 \pm 16,7 b$ & $256,5-395,6$ & $305,3 \pm 50,4 b$ \\
\hline Pacu & $90,2-139,0$ & $105,3 \pm 17,9 a$ & $394,5-491,2$ & $435,6 \pm 37,4 a$ \\
\hline Piraputanga & $47,3-83,7$ & $67,6 \pm 13,84 b$ & $209,3-314,9$ & $244,3 \pm 41,4 b$ \\
\hline Dourado & $61,3-147,2$ & $107,4 \pm 30,3 a$ & $266,5-529,5$ & $406,8 \pm 93,5 a$ \\
\hline Piauçu & $40,1-88,4$ & $61,6 \pm 16,5 b$ & $156,0-315,7$ & $237,7 \pm 56,2 b$ \\
\hline Pintado & $50,0-55,0$ & $51,5 \pm 1,91 b$ & $196,5-277,8$ & $230,1 \pm 27,1 b$ \\
\hline
\end{tabular}

* Média de 5 amostras analisadas em triplicata.

Valores na mesma coluna com letras diferentes apresentaram diferença significativa ao nível de $5 \%$.

DP = Desvio Padrão. 
Os dados fornecidos pela literatura têm mostrado que alimentos à base de carne e de ovos apresentam valores mais altos de colesterol, em relação aos produtos de laticínios $(4,5,6,11)$.

Níveis de colesterol sanguíneo não dependem somente do teor de colesterol dos alimentos, mas também do balanço/equilíbrio de ácidos graxos saturados e insaturados (16). Dietas contendo ácidos graxos e colesterol, porém em quantidades moderadas e predomínio dos ácidos graxos poliinsaturados exercem ação depressora sobre o colesterol e as lipoproteínas do plasma $(11,16)$. Animais marinhos, peixes e óleos de peixes, embora alguns apresentem alta taxa de concentração de colesterol, constituem a grande fonte fornecedora de ácidos graxos poliinsaturados da família ômega-3. A composição em ácidos graxos dos peixes de água doce depende do tipo de alimentação de que dispõem, apresentando longa variação qualitativa e quantitativa (1).

Comparando os valores médios da concentração do colesterol do tecido muscular das espécies estudadas verificou-se que o dourado e o pacu não apresentaram diferença significativa entre si em nível de 5\%, mas diferiram significativamente dos demais peixes. Entre os valores obtidos para a piranha, a piraputanga, o piauçu e o pintado não houve diferença significativa. Os resultados de colesterol obtidos para essas quatro espécies de peixe, quando comparados com dados encontrados por outros autores, revelaram que os valores foram compatíveis aos da espécie de água doce "Tilápia" (62,39 mg/100 g) e do "Caranguejo" (62,39 mg/100 g) (23).

O teor de colesterol encontrado para o pacu e dourado (respectivamente, 105,3 e $107,4 \mathrm{mg} / 100 \mathrm{~g}$ de amostra integral) mostrou-se alto em relação aos demais peixes analisados e em relação à carne bovina e suína (6). Comparativamente aos outros pescados, os teores obtidos para o pacu e o dourado do pantanal foram mais baixos do que os encontrados em alguns produtos cárneos, como o camarão $(5,17)$, lagosta, fígado e pele de frango $(4,11)$. Deve-se considerar, no entanto, que o teor de lipídio nas seis espécies de peixes estudadas é relativamente baixo, tendo sido encontrados nessas mesmas espécies de peixes $(7,9,10,21)$ ácidos graxos polinsaturados, especialmente eicosapentaenóico-C20:5- $\omega 3$ (EPA) e docosahexaenóico-C22:6 $\omega 3$ (DHA).

\section{CONCLUSÃO}

Os valores médios de lipídios totais obtidos nas amostras analisadas 
(peixes de água doce) ficaram abaixo dos valores encontrados na literatura para algumas espécies de peixes de água salgada.

A concentração de colesterol encontrada nos peixes estudados enquadrouse na faixa entre 51,5 a $107,4 \mathrm{mg} / 100 \mathrm{~g}$ de amostra integral (base úmida), sendo que o pintado apresentou o teor médio mais baixo e o dourado 0 mais alto. $O$ dourado e o pacu apresentaram concentração de colesterol significativamente mais alta do que a encontrada para piranha, piraputanga, piauçu e pintado.

O pintado apresentou teores mais baixos de lipídios totais e de colesterol em comparação com os demais peixes estudados.

Considerando os valores de colesterol observados na literatura para alguns pescados e determinadas partes comestíveis da carne bovina e suína, as amostras dos peixes pacu e dourado analisados apresentaram teores elevados.

\section{Abstract \\ CHOLESTEROL LEVELS AND TOTAL LIPIDS IN SIX SPECIES OF FISH CAPTURED IN "PANTANAL" REGION OF MATO GROSSO DO SUL STATE}

The objective of this work was to determine the cholesterol and total lipids content in the edible portion (muscular tissue) of six species of fish, captured in the "Pantanal region of Mato Grosso do Sul State (Brazil). The studied species were the pacu (Piaractus mesopotamicus), the piranha (Pygocentrus nattereri), the dourado (Salminus maxillosus), the piraputanga (Brycon orbigynanus), the piauçu (Leporinus macrocephalus) and the pintado (Pseudoplatystoma coruscans). The method for determination of cholesterol was the colorimetric of BOHAC et al. and for the total lipids was the extraction method with organic solvent and gravimetry. With relationship to the values of total lipids, the average content obtained for the six species of studied fish were in the range of 1,0 to $6,7 \mathrm{~g} / 100 \mathrm{~g}$ of muscular tissue of the fish, and the pintado presented smaller concentration and the piraputanga was revealed as the largest lipid source. The cholesterol concentration, in $\mathrm{mg} / 100 \mathrm{~g}$ of muscular tissue (raw base) was higher for the dourado $(107,4 \mathrm{mg} / 100 \mathrm{~g})$ and lower for the pintado $(51,5 \mathrm{mg} / 100 \mathrm{~g})$.

KEY WORDS: CHOLESTEROL; TOTAL LIPIDS; FISH.

\section{REFERÊNCIAS}

1 BELDA, M.C.L.; CAMPOS, M.A.P. Ácidos graxos essenciais em nutrição: uma visão atualizada. Ciênc. Tecnol. Aliment., Campinas, v.11, n.1, p.5-35, 1991. 
2 BLIGH, E.G.; DYER, W.J. A rapid method of total lipid extraction and purification. Can. J.Biochem. Physiol., v.37, n.8, p. 911-917, 1959.

3 BOHAC, C.E.; RHEE, K.S.; CROSS, H.R.; ONO, K. Assessment of methodologies for colorimetric cholesterol assay of meats. J. Food Sci., Chicago, v.53, n.6, p.1642-1644, 1988.

4 BRAGAGNOLO, N. Determinação dos teores de colesterol em carnes, ovos e massas com ovos. Campinas, 1992. 105 p. Dissertação (Mestrado), Faculdade de Engenharia de Alimentos, Universidade Estadual de Campinas.

5 BRAGAGNOLO, N.; RODRIGUEZ-AMAYA, D.B. Teores de colesterol em carne suína e bovina e efeitos do cozimento. Cienc. Tecnol. Aliment.,v.15, n.1, p. 11-17, jan/jun. 1995.

6 BRAGAGNOLO, N.; RODRIGUEZ-AMAYA, D.B. Otimização da determinação de colesterol por CLAE e teores de colesterol, lipídios totais e ácidos graxos em camarão rosa (Penaeus brasiliensis), Ciênc. Tecnol. Aliment., Campinas, v.17, n.3, p.275-280, 1997.

7 CAÇÃO, S.S.; RAMOS FILHO, M.M. Caracterização química e composição de ácidos graxos da fração lipídica do corimbatá (Prochilodus scrofa) e do piauçu (Leporinus macrocephalus) capturados na região pantaneira de Mato Grosso do Sul. In: ENCONTRO DE INICIAÇÃO CIENTÍFICA, 6, Goiânia, 1997. Resumos... Goiânia: EIC, 1997. p. 303.

8 CHAMIZO, J.O. Brain tinglers. J. Chem. Ed., v.59, n.2, p. 151159, 1982.

9 FERREIRA, A.A.; RAMOS FILHO, M.M. Caracterização química e composição de ácidos graxos da fração lipídica do pintado (Pseudoplatystoma coruncans) e do cachara ( $P$. fasciatum) capturados na região pantaneira de Mato Grosso do Sul. In: ENCONTRO DE INICIAÇÃO CIENTÍFICA, 7, Uberlândia, 1998. Resumos... Uberlândia: EIC, 1998. p.419.

10 FLÔRES, S.M.; RAMOS FILHO, M.M.; RAMOS, M.I.L.; HIANE, P.A. Caracterização química e composição de ácidos graxos da fração lipídica do pacu (Piaractus mesopotamicus) e da piranha (Serrasalmus nattereri) capturados na região pantaneira de Mato Grosso do Sul. In: CONGRESSO BRASILEIRO DE CIÊNCIA E TECNOLOGIA DE ALIMENTOS, 16, Rio de Janeiro, 1998. Anais... Rio de Janeiro: CBCTA, 1998. p. 581-584. 
11 FRANCO, G. Tabela de composição química dos alimentos. 9. ed. Rio de Janeiro: Atheneu, 1998. 307 p.

12 GOMES, F.P. Curso de estatística experimental. 10. ed. Piracicaba: Nobel, 1982. 430 p.

13 HARRIS, W.S. Fish oils and plasm lipid lipoprotein metabolism in humans: a critical review. J. Lipid. Res., Bethesda, v.30, n.6, p. 785-807, 1989.

14 INSTITUTO ADOLFO LUTZ. Normas analíticas do Instituto Adolfo Lutz. 3. ed. São Paulo, 1985. 533 p.

15 KEYS, A. Diet and the epidemiology as coronary heart disease. J. Am. Med. Assoc. v.164, p. 1912-19, 1957.

16 KEYS, A.; ANDERSON, J.T.; GRANDE, F. Serum cholesterol response to changes in the diet. IV. Particular saturated fatty acids in the diet. Metabolism, v.14, p.776, 1965.

17 KRZYNOWEK, J. ; PANUNZIO, L.J. Cholesterol and fatty acids in several species of shrimp. J. Food Sci., v.54, n. 2, p.237-239, 1989.

18 MAZIER, M.J.P.; JONES, P.J.H. Dietary fat quality and circulating cholesterol levels in humans: a review of actions and mechanisms. Progr. Food Nutri. Sci., v.15, p. 21, 1991.

19 NATIONAL CHOLESTEROL EDUCATION PROGRAM. Report of the National Cholesterol Education Program expert panel on detection, evaluation and treatment of high blood cholesterol in adults. Arch. Int. Med., v.148, n. 1, p.36-69, 1988.

20 O'DEA, K.; TRAIANEDES, K.; CHISHOLM, K.; LEYDEN, H.; SINCLAIR, A.J. Cholesterol-lowering effect of a low - fat diet containing lean beef is reversed by the addition of beef fat. Am. J. Clin. Nutr., v.53, n. 3, p.491-494, 1990.

21 PERUCA, A.; RAMOS FILHO, M.M.; RAMOS, M.I.L.; HIANE, P.A. Caracterização química e composição em ácidos graxos da fração lipídica do dourado (Salminus maxillosus) e da piraputanga (Brycon orbigynanus) capturados na região pantaneira de Mato Grosso do Sul. In: SIMPÓSIO LATINO AMERICANO DE CIÊNCIA DE ALIMENTOS, Campinas, 1997. Resumos... Campinas: SLACA, 1997. p. 63.

22 SEARCY, R.L.; BERGQUIST, L.M. A new color reaction for the quantitation of serum cholesterol. Clin. Chim. Acta, v. 5, p. 192199, 1960. 
23 SERRÃO, L.H.C.; NUNES, M.L.; BRAGAGNOLO, N. Lipídios totais e colesterol em produtos pesqueiros frescos e processados. In: SIMPÓSIO LATINO AMERICANO DE CIÊNCIA DE ALIMENTOS, Campinas, 1997. Resumos... Campinas: SLACA, 1997. p. 67. 